\title{
Schmitt, Foucault, a guerra e o político
}

\section{Schmitt, Foucault, the war and the politician}

\author{
Jean-François Thibault ${ }^{1 *}$
}

\section{Resumo}

o presente artigo objetiva desenvolver como o pensamento filosófico de Foucault e Schmitt tematizam a importância da guerra na constituição do Político, mas busca também demonstrar que a par dessa semelhança temática, tanto em suas premissas como em suas conclusões os dois autores se distanciam, adotando Schmitt uma perspectiva moderna, ao contrário de Foucault que desenvolve sua reflexão numa chave contemporânea.

Palavras-chave: guerra, poder, político, filosofia.

\begin{abstract}
This article aims at developing the way how Foucault's and Schmitt's philosophical thought thematizes the importance concerning the war in the politician's constitution but it also searches demonstrating that, together with thematic resemblance, as well in their premises as in their conclusions, these two authors keep a certain distance between them, as Schmitt adopts a modern perspective, on the contrary of Foucault that develops his reflection in a contemporaneous key.
\end{abstract}

Key words: War. Power. Politician. Philosophy

... c'est un des traits fondamentaux des sociétés occidentales que les rapports de force qui longtemps avaient trouvé dans la guerre, dans toutes les formes de guerre, leur expression principale se sont petit à petit investis dans l'ordre du pouvoir politique. - Michel Foucault ${ }^{2}$

... ce sont, en effet, toujours des groupes humains concrets qui, au nom du Droit ou de l'Humanité ou de

1 * Professor do Departamento de ciência política da Université de Moncton. Tradução de Danilo Vaz-Curado R. M. Costa (UNICAP). Uma versão preliminar do presente texto foi publicada em Monde commun, vol. 1, no. 1, 2007, p. 114-129.

2 Michel Foucault : Histoire de la sexualité, volume 1: La volonté de savoir, Paris, Gallimard, 1976, p. 135.

Ano 13 • n. 1 • jan./jun. 2013 - 169 
l'Ordre ou de la Paix, luttent contre d'autres groupes humains concrets. - Carl Schmitt ${ }^{3}$.

É de bom, tom em filosofia política, opor a política e a guerra e fazer contrastar a calma da vida pacificada que testemunharia a existência de um vínculo social harmonioso com a violência das discórdias, a qual, por sua vez, ilustraria a ausência de um tal vínculo. Do meson que os gregos do período clássico louvavam ao contrato que celebram quanto aqueles os modernos, a convicção segundo a qual a política participaria principalmente de uma domestificação dos conflitos e de uma superação das diferenças efetuadas em vista de uma reconciliação que seria mais que um simples modus vivendi parece a mesma.

Mas será que não há aí, nessa instância que parece querer colocar a filosofia política a negar os conflitos e a evitar as diferenças, qualquer coisa como o medo de ver ressurgir a violência desses possíveis desacordos e das desordens que eles provocariam um horizonte insuperável? Em efeito, não se julgue que, em tais circunstâncias, a política findaria em toda sorte por não mais ser a política para, inversamente, naufragar imediatamente na guerra? Assim se encontraria afetada, pelo fato mesmo do trabalho de representação da ordem pacificada que é dada como tarefa da filosofia política, de abraçar uma démarche que apenas parece estar em condições de reconstituir as condições de inte-

Carl Schmitt : La notion de politique - Théorie du partisan [1932-1963], traduzido por Marie-Louise Steinhauser, Paris, Calmann-Lévy, 1972, p. 114. Sobre os vínculos entre Foucault e Schmitt, consultar Terray, Clausewitz, p. 110; Mika Ojakangas : « Sovereign and Plebs : Michel Foucault Meets Carl Schmitt », Telos, 119, 2001, p. 32-40; Beatrice Hanssen : Critique of Violence. Between Poststructuralism and Critical Theory, Londres, Routledge, 2000, p. 97-157; Miguel Vatter : « La politique comme guerre : formule pour une démocratie radicale? », traduzido por Badr El Fekkak, Multitudes, 9, mai-juin 2002. Consultado on-line em: http ://multitudes.samizdat.net/article.php3?id_article=35; Marie Gaille-Nikodimov : « L'ordre conflictuel du politique : une formule ambiguë. Schmitt et Foucault, lecteurs de Machiavel », Multitudes, 13, été 2003. Consultado on-line em: http://multitudes.samizdat.net/article.php3?id_article $=1108$

170 - Universidade Católica de Pernambuco 
ligibilidade geral do agir político...na condição de suprimir a alma discordante 4 . Para esta filosofia política, o conflito e o diferente permaneceriam assim largamente indecidíveis posto que sua aparição assinalaria, de fato como de direito, o limite de uma representação ideal acessível justamente aí, isto é, nesta desordem que ela não consegue precisamente exprimir sua fronteira tão temida. Toda a transgressão conduziria aquele que ousasse se aventurar para além desta fronteira à perdição.

Todavia, a impressão permanece quando o conflito ou o diferente são assim ocultados e colocados fora da tematização da filosofia política algo de decisivo permanece fora do quadro 5 . Tanto para os gregos como para os modernos se poderia dizer que esta facticidade da política seja, apesar de tudo o que ela poderia implicar como prova para a reflexão, indispensáveis a uma compreensão do político verdadeiramente satisfatório ${ }^{6}$ ?

Postulando que aí se trata de um imperativo ao qual deve poder se confrontar com a filosofia política, notadamente num contexto ou ideia segundo a qual uma comunidade que seja a extensão do orbe do mundo estaria atualmente a inventar o ganho rápido dos espíritos, ${ }^{7}$ o objetivo deste artigo é de explorar o caráter de hipótese relativa à relação existente entre a política e a guerra que Michel Foucault desenvolveu em seus cursos de 1976 no Colégio de França, intitulados, É preciso defen-

4 Roberto Esposito : « Réflexions sur l'impolitique », Philosophie, 51, 1996, p. 73

5 Ibid, p. 71.

6 Acerca do pensamento grego, consultar Nicole Loraux : La cité divisée. L'oubli dans la mémoire d'Athènes, Paris, Payot, 1997. Sobre o pensamento moderno, consultar, Chantal Mouffe : Le politique et ses enjeux, Paris, La Découverte/M.A.U.S.S., 1993. Desenvolvemos este hipótese em relação com a reflexão que consagrada John Rawls às relações internacionais em Jean-François Thibault : "L'interprétation limitée du politique dans "The Law of Peoples" de John Rawls ", Politique et Sociétés, 20, 2-3, 2001, p. 159-179.

7 Consultar Étienne Tassin : Un monde commun. Pour une cosmo-politique des conflits, Paris, Seuil, 2003 
der a Sociedade. Mais especificamente, apresentar-se-á inicialmente o que ele identifica como a formulação clássica da relação entre guerra e política, tal como ela se encontra no estrategista prussiano Carl von Clausewitz. Deter-nos-emos em seguida ao que Foucault tematiza como sendo uma reviravolta desta relação entre guerra e política. Após constatar essa reviravolta à luz da reflexão de um outro crítico da filosofia política liberal, Carl Schmitt, colocar-nos-emos mais francamente no quadro da reflexão sobre os dispositivos saber/poder que ocuparam Foucault durante este mesmo período.

\section{A subordinação da guerra à política em Clausewitz}

Clausewitz aparece aqui como uma figura particularmente importante, posto que ele formaliza de toda sorte a representação convencionalmente aceita dessa relação entre a política e a guerra. Relação que faz não apenas da guerra um simples meio da política - ainda que um meio por demais absolutamente essencial - mas, igualmente um meio que apenas possui outro fim, a paz, pela qual se regraria num resultado comum, o conflito ${ }^{8}$.

É conhecida a fórmula da guerra como simples continuação, persecução, manifestação ou realização da política Estatal por outros meios com a qual Clausewitz buscava fundar a racionalidade e a inteligibilidade da guerra nas relações de subordinação que essa devia necessariamente conservar em face da política9 Para essa última, a fórmula assinala em efeito que a política representa naturalmente "a matriz na qual a guerra se desenvolve ${ }^{10}$; matriz que precisamente forneceria ' $\mathrm{O}$ meio inicial da guerra'" A guerra seria, pois, aqui, de parte em parte, um ato político, ao

\footnotetext{
8 Carl von Clausewitz : De la guerre [1832-1834/1952], traduit par Denise Naville, Paris, Minuit, 1955, p. 558

$9 \quad$ Ibid., p. 67.

$10 \quad$ Ibid., p. 145.

$11 \quad$ Ibid., p. 59

172 - Universidade Católica de Pernambuco
} 
qual penetraria "o ato de guerra inteiro exercendo uma influência constante sobre ele". ${ }^{12}$ Mesmo a conduta da guerra, seria, ao menos "em suas grandes linhas", a persecução da própria política. ${ }^{13}$ Para Clausewitz, a guerra assemelha-se, pois, à política ${ }^{14}$, posto que ela tem e diz respeito e constitui mesmo uma dimensão dessas relações políticas que relacionam o conjunto dos Estados. Em suma, a guerra seria simplesmente como a "parte de um todo que difere dele"15, como uma parte de política que "empunha a espada no lugar da pluma" 16 e "se lança à batalha ao invés de redigir notas" ${ }^{17}$.

Nenhuma dúvida há, de que seja a política quem determina aqui os contornos, os motivos e os fins da guerra. Nas suas circunstâncias, isso que não seria precisamente nada mais que um meio, entre os diversos outros disponíveis, tal como a diplomacia, por exemplo, para alcançar os objetivos fixados pela política. Um meio pois contrariamente a política que repousa sobre o diálogo, sobre a astúcia e sobre a moderação, a guerra supõe quanto a ele, e é precisamente o que residiria, segundo Clausewitz, sua nota específica, o uso da violência, da força e da desmedida. A guerra é, com efeito, um modo de regrar as diferenças pelo sangue e, para nossa estratégia, é ademais unicamente "nisso que ela difere dos outros conflitos"18.

Enquanto instrumento da política, e sob pena de ceder fácil demais o terreno ao irracional alimentado pelas paixões e o acaso, a guerra não poderia portanto ser pensada independentemente de um entendimento político subjetivo equivalente para Clausewitz à "Inteligência do Estado personificada" ${ }^{19} \mathrm{e}$ corres-

\footnotetext{
Ibid., p. 66-67.

Ibid., p. 710.

Ibid., p. 145.

Ibid., p. 703-704

Ibid., p. 710.

Ibid., p. 706.

Ibid., p. 145

Ibid., p. 68
} 
pondente mais ou menos a isso que nós compreendemos atualmente evocando a noção de interesse nacional ${ }^{20}$. Neste contexto, a política exprimiria "o ponto de vista o mais elevado da conduta da guerra" 21; o qual deveria tudo medir a seu "condão" 22 . Assim, nessa definição da guerra que quer todos os fins práticos como uma "decisão pelas armas" ${ }^{23}$, Clausewitz sugera a existência de uma "separação rigorosa entre a paz e a guerra" 24.

Portanto, pode-se afirmar que há efetivamente para Clausewitz uma gramática da guerra (como haveria uma gramática da diplomacia) distinta daquela da política, de onde decorre a ideia que existe uma separação rigorosa entre a paz e a guerra - a ideia mesma de uma continuidade entre guerra e política não assinala igualmente, como nota alhures ele mesmo ${ }^{25}$, que uma e outra participam da base de uma mesma lógica. Essa lógica indicaria que tanto a guerra quanto a política se inscrevem finalmente no seio de uma unidade que nada mais seria que esse "duelo numa escala mais vasta" que vê se afrontar os Estados, as nações e os governantes. ${ }^{26}$

É precisamente no contexto de um tal afrontamento que permaneceria o risco de ver a guerra assumir o triunfo sobre a política ascedendo aos extremos. Deslocando face à forma absoluta de uma "luta de vida e morte" ${ }^{27}$ provocada por um "arrebatamento das paixões" ou por uma "indeterminação da vontade" ${ }^{28}$ uma tal ascensão aos extremos traduziria então a incapacidade na qual se

\footnotetext{
20 Raymond Aron: Penser la guerre: Clausewitz, volume 2, L'âge nucléaire, Paris, Gallimard, 1976, p. 227

${ }_{21}$ Clausewitz, De la guerre, p. 706.

22 Ibid., p. 59, 710.

23 Ibid., p. 79.

24 Raymond Aron: Penser la guerre: Clausewitz, volume 1, L'âge européen, Paris, Gallimard, 1976, p. 109-110, 435.

25 Clausewitz, De la guerre, p. 703

26 Ibid., p. 51, 703.

27 Ibid., p. 705.

28 Aron, Penser la guerre, volume 1, p. 184, 197.

174 - Universidade Católica de Pernambuco
} 
encontraria a política de conseguir controlar este instrumento que é a guerra. Numa tal situação, que para Clausewitz permanece plausível, apesar de seu caráter execepcional e na qual, alimentado pelos únicos motivos de uma guerra que terminaria por "seguir suas próprias leis como algo totalmente independente"29, a hostilidade se tornaria pura e a violência extrema, e "o ponto de vista político desapareceria" 30 e a guerra tomaria finalmente o "lugar da política" 31 .

Tal parece ser o horizonte sobre o qual abre, para além da subordinação da guerra à política, a ideia de uma continuidade entre a guerra e a política; uma continuidade que confere a essa última o privilégio da vitória. Mas de qual vitória se trata justamente? Pois, apesar de sua resistência a querer explorar as conseqüências de uma inversão da fórmula e, então, de querer explorar a possibilidade de uma "subordinação" da política à guerra - trata-se aí, segundo Clausewitz, de uma pura absurdidade ${ }^{32}$ - e apesar de sua insistência em fazer da paz o termo que põe efetivamente "um fim aos negócios de guerra" ${ }^{33}$, a aparência entre a guerra e a política que a utiliza estrategicamente supõe a ideia de uma continuidade, não abre igualmente a porta a outras implicações, como aquela que nos autoriza a conceber a hipótese de uma reversão dessa relação de subordinação da guerra à política?

Se, com efeito, a guerra conserva efetivamente uma certa especificidade usando da violência armada, o fato permanece que uma tal ação supõe igualmente, do fato de sua subordinação à política, um campo de atores e, por vezes mesmo, de objetivos que, seriam para falar propriamente "idênticos"34. Insistindo que a guerra apenas é um novo modo que se adiciona àqueles que

\footnotetext{
29 Clausewitz, De la guerre, p. 66-68.

30 Ibid., p. 705

31 Ibid., p. 66.

${ }^{32}$ Ibid., p. 706

${ }^{33}$ Ibid., p. 71.

${ }^{34}$ Emmanuel Terray: Clausewitz, Paris, Fayard, 1999, p. 100.
} 
dispõem os Estados, as nações e os governantes nas relações políticas que eles estabelecem uns com os outros, Clausewitz entende afirmar de um só golpe que a guerra não faz cessar essas relações políticas. A guerra não transforma essas relações em algo totalmente diferente, mas essas relações continuam a existir em sua essência, quaisquer que sejam os meios que os Estados, as nações e os governantes se sirvam, e que os principais fios que afluem através dos eventos de guerra e aos quais eles se fixam apenas são lineamentos de uma política que se persegue através da guerra até a $\operatorname{paz}^{35}$.

À luz de tais circunstâncias, isto é, disso que os "lineamentos" da política se distinguem no coração mesmo da guerra ${ }^{36}$, não poderíamos inferir que toda vida política é em última instância atravessada por um conflito e que, ao invés de ser a política que dá seu sentido à guerra, essa não possa finalmente ser a guerra, a qual apenas seria, no fundo, um modo um pouco "mais exigente de negociar" ${ }^{37}$, que confere seu sentido à política?

Para Clausewitz, uma tal conclusão não poderia ser tirada posto que a verdadeira política, a única que justamente estaria em condições de engendrar a guerra tal qual ela a compreende, é aquela que existe entre os Estados, as nações e os governantes. Nessas circunstâncias, querer reverter a fórmula consistira em adotar uma outra definição da política que incluiria, por exemplo, a política interior. À imagem da Revolução Francesa, uma tal política interior colocaria em cena uma vida civil feita de uma proliferação de "atividades, de intrigas e de afrontamentos, de lutas e de sucessos, de crainte e de esperança, de terror e de alegria". Mas, precisamente, segundo Clauzewitz, isso significaria incluir em nossa compreensão da política, isso que apenas seria, de fato, "uma anomalia" ou mesmo um "desvio mórbido da ação" 38 .

\footnotetext{
${ }^{35}$ Clausewitz, De la guerre, p. 703.

${ }^{36}$ Ibid., p. 145.

${ }^{37}$ Ibid., p. 685.

38 Carl von Clausewitz: Écrits et lettres, traduit par Marie-Louise Stein176 - Universidade Católica de Pernambuco
} 


\section{A inversão da fórmula de Clausewitz}

Para Foucault, precisamente porque é preciso parar de conceber a política apenas à luz de um modelo jurídico estreitamente associado ao princípio da soberania e fazendo-o à gênese ideal deste Estado territorial reivindicando, "por sua própria conta", segundo a fórmula de Max Weber, "o monopólio da violência física legítima" ${ }^{39}$, ele deveria adotar uma outra definição desta conduzindo-o a inverter a fórmula de Clausewitz que faz da guerra um puro "ato de soberania" ${ }^{40}$. Isso que ele precisa antes considerar, é ademais a possibilidade de que a política não seja finalmente nada mais que a guerra continuada sob outra forma. Isso que ele precisa, pois considerar, é fazer da política, um puro ato de guerra. Portanto, liberar a filosofia política do princípio da soberania, isto é, cortar a cabeça do rei uma vez por todas ${ }^{41}$ de modo a politizar o espaço despolitizado que circundava até então o soberano. Nessas circunstâncias, a hipótese de uma tal inversão significaria fundamentalmente três coisas. ${ }^{42}$

Isso inicialmente significaria "que as relações de poder ... tem essencialmente por ponto de fixação uma certa relação de força estabelecida a um dado momento, historiamente precisável, na

hauser, Paris, Gallimard, 1976, p. 406-407. Cité par Terray, Clausewitz, p. 103

39 Michel Foucault: "Résumé de cours [1976] », in Michel Foucault : « Il faut défendre la société ». Cours au Collège de France, 1976, Paris, Hautes Études/Gallimard/ Seuil, 1997, p. 239. Max Weber : Le savant et le politique [1917-1919], traduzido por Julien Freund, Paris, Plon, 1959, p. 125. Os itálicos estão no texto.

40 Gérard Mairet : Le principe de souveraineté. Histoire et fondements du pouvoir moderne, Paris, Gallimard, 1997, p. 119.

${ }^{41} \quad$ Foucault, La volonté de savoir, p. 117.

42 Deixo aqui de lado a historiografia na qual Foucault se filia, isto é, seu mergulho na corrente por ele nomeada de historicismo político, para antes me interessar por suas reflexões analíticas concernentes à relação entre a guerra e a política. Acerca desta historiografia, consulte-se Franck Lessay : «Joug normand et guerre des races : de l'effet de vérité au trompe-l'œil ", Cités, 2, 2000, p. 53-69. 
guerra e pela guerra". Nestas circunstâncias, efetivamente pode-se pensar pouco que "o poder político cessa a guerra", isto significaria, sobretudo que esta démarche de pacificação "teria por função re-inscrever perpetuamente essa relação de força, por meio de uma guerra sileciosa" que atravessaria de lado a lado o corpo social.

Por conseqüência, considerar uma tal hipótese significaria, em seguida, que "no interior desta paz civil, as lutas políticas, os afrontamentos a propósito do poder, com o poder, pelo poder, as modificações das relações de força ... tudo isso... apenas deveria ser interpretado como a continuação da guerra". Assim, a história da paz e das instituições sobre as quais isso reposaria apenas consistiria na prática num "deslocamento da guerrra" que persistiria, mas sob uma forma menos absoluta porque aparentemente menos violento. Assim, considerar esta hipótese significarai enfim que "a decisão final apenas pode vir da guerra, isto é, da prova de força onde as armes, finalmente, deveriam ser julgadas". Em suma, a última batalha, assinalando o fim da guerra, marcaria para Foucault a suspensão definitiva do exercício do poder. Dito de outra forma, esta violência marcaria "o fim do político" e não simplesmente o fim da guerra enquanto tal ${ }^{43}$.

Se a guerra representa, pois efetivamente a "as relações de força nuas", então a pol[itica tal como se lha representa idealmente a filosofia política no horizonte do princípioda soberania, isto é, no horizonte da paz e das instituições sobre as quais esta paz repousa, não seria nada mais que a a máscara dissimulando a permanência de tais relações de força que o poder tentaria simplesmente, deste maneira, fazer mais aceitáveis, ou, ainda, mais toleráveis. ${ }^{44}$ Por trás desta pseudo vitória sobre a violência cotidiana e sobre a guerra privada que testemunha, ao sair da idade média, da concentração nas mãos de um poder central de práticas e de instituições de guerra que se viram deslocadas à fronteira,

\footnotetext{
43 Foucault, "Il faut défendre la société », p. 16-17

44 Foucault, La volonté de savoir, p. 190, 113

178 - Universidade Católica de Pernambuco
} 
isto é, "aos limites exteriorres das grandes unidades políticas" 45 , apenas trata-se na prática da "evicção do fato da dominação e de suas conseqüências" nas concepções e nas representações que nós nos fazemos da paz $^{46}$.

É por isto que é conveniante antes, segundo Foucault, aprofundar a hipótese consistente em pensar a política em função das relações de força que a atravessa constantemente e então tentar identificar o "princípio de inteligibilidade da ordem, do Estado, de suas instituições e de sua história" na "confusão da guerra" e na "lama das batalhas" ${ }^{47}$ antes que nisto que sob a forma do direito apenas representa segundo toda a verossimilhança a aparente conjuração visando precisamente dissimular o fato de que "no meio de suas rodas" a paz faz ainda e sempre "silenciosamente a guerra" 48 .

A primeira vista, e mesmo que não o mencione, Foucault parece aqui claramente próximo da reflexão de Carl Schmit, para quem "são, com efeito, sempre grupos humanos concretos que, em nome do Direito ou da Humanidade ou da Ordem ou da Paz, lutam contra outros grupos humanos concretos"49. Para Schmitt como, para Foucault, o plano de fundo desses contratos que são reputados por fundar a política moderna, teriam em efeito, algo

45 Foucault, «Il faut défendre la société », p. 41-42.

46 Ibid., p. 24

47 Ibid., p. 40-41

48 Ibid., p. 43.

49 Schmitt : La notion de politique, p. 114. Sur les liens entre Foucault et Schmitt, consulter Terray, Clausewitz, p. 110; Mika Ojakangas : « Sovereign and Plebs : Michel Foucault Meets Carl Schmitt », Telos, 119, 2001, p. 32-40; Beatrice Hanssen : Critique of Violence. Between Poststructuralism and Critical Theory, Londres, Routledge, 2000, p. 97-157; Miguel Vatter : «La politique comme guerre : formule pour une démocratie radicale? », traduit par Badr El Fekkak, Multitudes, 9, mai-juin 2002. Consulté en ligne à l'adresse suivante : http ://multitudes.samizdat.net/article.php3?id_article $=35$; Marie Gaille-Nikodimov : « L'ordre conflictuel du politique : une formule ambiguë. Schmitt et Foucault, lecteurs de Machiavel », Multitudes, 13, été 2003. Consulté en ligne à l'adresse suivante : http ://multitudes. samizdat.net/article.php3?id_article $=1108$ 
como "uma ética da guerra civil" 50 . Tanto para um, como para o outro é, pois, a guerra que daria finalmente seu sentido à política.

Mas, contrariamente a Schmitt, que se filia aqui a Clausewitz, Foucault não raciocina em termos de interior e de exterior e não procura pois reconduzir a guerra às fronteiras exteriores do Estado, lá onde somente se praticaria a político no "sentido pleno" ${ }^{51}$. Foucault não raciocina, como Schmitt tende a fazê-1o, a partir de um modelo aparentemente normal da vida política que arriscaria simplesmente, mas por assim dizer a todo momento, de cair numa guerra civil ou ainda num estado de exceção tomando mais ou menos a forma de uma guerra civil legal ${ }^{52}$. Desse modo, as relações de força que atravessariam o corpo social não poderiam ser convertidas por Foucault numa forma de guerra civil latente. Para ele, de fato, a guerra aparece precisamente como "o que permite o direito existir" 53 , enquanto que para Schmitt, ao contrário, a guerra civil aparece essencialmente como a suspensão do direito, o qual traduziria a «desintegração do Estado»» ${ }^{54}$.

Assim, procurando, como Schmitt, decifrar a guerra sob a paz, Foucault dele não obstante se afasta, posto que ele persiste justamente em apreciar a inversão da relação entre a política e a guerra à luz do modelo jurídico da soberania. Isto é, contrariamente a Foucault, Schmitt procura sempre o poder ao lado de seu

50 Carl Schmitt : Parlementarisme et démocratie [1923], traduit par JeanLouis Schlegel, Paris, Seuil, 1988, p. 150

51 Schmitt, La notion de politique, p. 45.

52 Sur cette notion de "guerre civile légale », on consultera Giorgio Agamben: «Réflexion sur l'état d'exception», Le Monde, 12 décembre 2002 ainsi que Giorgio Agamben : État d'exception. Homo Sacer, II, 1, traduit par Joël Gayraud, Paris, Seuil, 2003.

53 Consulter Diego Venturino : «À la politique comme à la guerre? À propos des cours de Michel Foucault au Collège de France (1976) », Storia della Storiografia, 23, 1993, p. 138.

54 Schmitt, La notion de politique, p. 88. Sans compter que, pour Schmitt, « les troubles » qui se développent à l'interne ne seraient pas susceptibles de voir se développer une "discrimination de l'ami et de l'ennemi » (Ibid., p. 67). Consulter Gaille-Nikodimov, « L'ordre conflictuel du politique $»$.

180 - Universidade Católica de Pernambuco 
centro ou de sua cabeça, precisamente no lado da decisão, isto é, onde se decide, com toda legalidade a "situação excepcional" 55 . Exceção pertubadora e que suspende a ordem política, certamente, "em vista do restabelecimento" dessa ordem e precisamente em vista do retorno à uma situação normal que, para Schmitt, permanece a "condição necessária para que as normas de direito sejam reconhecidas" ${ }^{56}$.

Foucault, ao contrário, procura explicitamente se subtrair a esse princípio da soberania, posto que a questão não consiste justamente para ele em se interrogar para determinar "no nível da intenção ou da decisão" que constituem aqui o horizonte de Schmitt "que, então tem o poder" ${ }^{57}$ e de qual modo esse poder se organiza, por assim dizer, mecanicamente, "em torno e a partir da existência física do soberano" 58 . Enfim, enquanto que para Schmitt o conceito de política não se presta a uma interpretação pluralista à medida que a natureza específica do político - que não remete aqui a uma domínio de atividade particular, mas ao "grau de intensidade de uma associação ou de uma dissociação de seres humanos" ${ }^{59}$ - não poderia ser verdadeiramente apreciada ou mesmo "tomada emconsideração" ${ }^{60}$, para Foucault, bem ao contrário, as relações de poder não estariam simplesmente em posição "de exterioridade" ou em posição de "superestrutura" ${ }^{11}$ face a outros tipos de relações sociais e isso seria precisamente pela razão que ele deveria ler o

55 Carl Schmitt : Théologie politique. Quatre chapitres sur la théorie de la souveraineté [1922] et Théologie politique II. Une légende : la liquidation de toute théologie politique [1969], traduit par Jean-Louis Schlegel, Paris, Gallimard, 1988, p. 15.

56 Schmitt, La notion de politique, p. 87. Consulter également Étienne Balibar: "Le Hobbes de Schmitt, le Schmitt de Hobbes ", dans Carl Schmitt: Le Léviathan dans la doctrine de l'État de Thomas Hobbes. Sens et échec d'un symbole politique [1938], traduit par Denis Trierweiler, Paris, Seuil, 2002, p. 38.

57 Foucault, «Il faut défendre la société », p. 25.

58 Ibid., p. 32.

59 Schmitt, La notion de politique, p. 79.

60 Ibid., p. 86.

${ }^{61}$ Foucault, La volonté de savoir, p. 123-124. 
conjunto dessas relações imanentes à luz de uma "ordem de batalha" ${ }^{62}$.

\section{Guerra e poder}

Para além da proximidade que pode existir entre Schmitt e Foucault quanto à relação quase orgânica que estabelece a guerra e a política, a pesquisa de Foucault se inscreve aqui, bem claramente, na continuidade de suas pesquisas, contemporâneas aos cursos de 1976, portanto, sobre a analítica do poder. A esse respeito, ela representa alhures o outro componente, o componente de poder estratégico, ao invés do poder disciplinar. Ambos os componentes, estratégico e disciplinar - que correspondem aqui ao que ele identificava como um esquema guerra-repressão oposto ao clássico esquema contrato-opressão - fundindo-se, por assim dizer, um no outro tal como os dois braços armados do poder que tanto o direito como a verdade são fundamentais para ele.

Guerra e repressão constituiriam de toda sorte para Foucault os dois eixos em torno dos quais o poder moderno seria finalmente articulado: um reprimindo, o outro guerreando; um apoiando-se sobre a produção de normas de verdade, o outro apoiando-se sobre a produção de regras de direito e ambos desenvolvendo-se sobre um modo que apareceria eminentemente polêmico, como o "efeito da simples persecução de uma relação de dominação" ${ }^{63}$. Nessa face estratégica, o poder seria exercido, segundo Foucault, por detrás da via do direito e sobre a base de um "modelo jurídico de soberania". O qual, para além do modelo disciplinar e da via da verdade, teria servido de "código" a partir do qual esse mesmo poder se apresentaria e teria por fim útil prescrever "o que se pensa", mascarando alhures os "fatos e procedimentos" que são os seus ${ }^{64}$.

\footnotetext{
${ }^{62}$ Foucault, «Il faut défendre la société », p. 41.

${ }^{63}$ Ibid., p. 17.

${ }^{64}$ Foucault, La volonté de savoir, p. 116.

182 - Universidade Católica de Pernambuco
} 
A inteligibilidade de um tal poder descentrado não remeteria a um objeto determinado e suscetível de fazer objeto de um teorização, que, no "domínio específico que formam as relações de poder" e a isso que Foucault caracterizaria como uma analítico da poder $^{65}$, isto é, esses mecanismos sobre os quais repousaria o exercício do poder. Nessas criscunstâncias, a análise do curso de 1976 apenas versaria sobre a guerra propriamente falando desde a perspectiva da guerra, assim como sobre o jogo estratégico que essa última supõe àquele que reflete, fala ou age na perspectiva de uma permanência da guerra ${ }^{66}$. Essa permanência da forma guerra compreendida "para além e aquém da batalha" 67 não ilustraria nada mais que a generalização das relações de poder quando aqueles que estão fora dos códigos políticos convencionais que representam a lei, a norma e a soberania. É, pois, a "trama epistemológica" ${ }^{68}$ que representa essa generalização como instrumento de análise da história do poder que retém a atenção de Foucault.

Isso que se trata para ele de pôr em evidência pelo intermediário de uma tal analítica do poder político como continuação da guerra, é que não se faz tanto "a guerra para escrever a história, mas que se escreve a história para fazer a guerra" ${ }^{99}$. A história apenas seria fundamentalmente o cálculo de uma relação de força e, para além da dicotomia dos vencedores e dos vencidos, apenas seria um reflexo da fragmentação do

\footnotetext{
$65 \quad$ Ibid., p. 109.

66 Foucault, "Il faut défendre la société», p. 145. Consultar igualmente Daniel Defert : "Le "dispositif de guerre" comme analyseur des rapports de pouvoir », em Jean-Claude Zancarini (textes reunidos por) : Lectures de Michel Foucault, volume 1: À propos de "Il faut défendre la société », Lyon, ENS Éditions, 2001, p. 63.

67 Foucault, «Il faut défendre la société », p. 141.

68 Paolo Napoli : «Michel Foucault et les passions de l'histoire [1993]», traduzido por Judith Revel, Futur antérieur, 18, 1993/4. Consultado online no seguinte endereço http://multitudes.samizdat.net/article. php3?id_article $=537$.

69 Ibid.
} 
corpo social, tomados os percursos de uma guerra permanente e generalizada que atravessaria "todo o corpo social e toda a história do corpo social" ${ }^{70}$.

É assim, para se libertar dos fios tecidos pelo modelo jurídico-político do poder, isto é, para se afastar de uma leitura da história que se desenrola no interior de um Estado que teria expulsado a violência às suas fronteiras e que estaria então pacificados, que Foucault avança a hipótese da política como um puro ato de guerra. Afinal de contas, o poder não é nada mais para ele que o nome que se "presta para uma situação estratégica complexa numa sociedade" ${ }^{71}$. Se, de modo assaz convencional, a guerra aparece como a "grade de inteligibilidade" por excelência da perturbação e da suspensão da ordem política, não poderia ela, igualmente como sugere a leitura que Foucault faz de Boulainvilliers, nos "permitir determinar a relação de força que mantém permanente uma relação de direito" $72 ?$

Após ter sido para a filosofia política um objeto político, as relações de poder aparecem aqui como um objeto histórico no seio do qual a guerra constituiria a "matriz da verdade", seja de uma vez "isso a partir do qual fala o discurso e isso que ele fala". ${ }^{73}$ Mesmo a história filosófico-política, por exemplo, que conta Thomas Hobbes no Leviatã, ou ainda, mais próximo de nós, aquela que nos conta John Rawls em sua Theory of Justice, não seria um e outra nada mais que a história do poder que o poder se conta a si mesmo. Assim, o discurso histórico torna-se nessas circunstâncias uma das "peças da estratégia" ${ }^{74}$ permitindo dizer o direito e a paz e em continuação, mas de modo subreptício, fazer

\footnotetext{
70 Foucault, «Il faut défendre la société », p. 143-144.

71 Foucault, La volonté de savoir, p. 123.

72 Foucault, «Il faut défendre la société », p. 144.

73 Ibid., p. 146.

74 Consulter Lawrence Olivier : Michel Foucault. Penser au tempsnihilisme, Montréal, Liber, 1995, p. 119
} 
a guerra. Ao invés dessa leitura de uma política que aparece, pois "sem história" 75 Boulainvilliers teria proposto uma política da história como dominação, decifrando as lutas que atravessariam "todas as instituições do direito e da paz" ". A guerra contada pela história do direito e da paz apenas seria aqui "a história atravessada por esta guerra que ela conta" 77 .

Por oposição a uma «lode do poder acerca de si próprio» ${ }^{78}$, Foucault distingue, segundo Boulainvilliers uma perpétua relação de força que representaria algo como a substância mesma da história. É essa "relação historicamente indefinida, indefinidamente densa e múltipla de dominação ${ }^{79}$ que, na prática, revela o que não seria nunca nemo direito, nem a soberania enquanto horizonte verdadeiramente idealizado da paz e do armistício político. Com efeito, posto que, por princípio não se escapa das relações de força e de dominação, não se sairia nunca da história que, tomando precisamente nascimento na alma discordante do político. Bem ao contrário das pretensões da filosofia política em ocupar uma posição "de árbitro, de juiz ou de testemunha universal" ${ }^{\prime \prime 0}$, a história não ofereceria finalmente nada mais para Foucault que uma "guerra que ele próprio realiza ou que passa por ele" 81 .

\section{Conclusão}

O que pensar desta aproximação da política como relação de guerra? A hipótese é fecunda com respeito à situação na

\footnotetext{
75 A expressão é de Loraux, La cité divisée, p. 49.

76 Foucault, «Il faut défendre la société », p. 153.

77 Ibid., p. 155.

78 Ibid.

79 Ibid., p. 96.

80 Michel Foucault : "Questions à Michel Foucault sur la géographie [1976] », e m Michel Foucault : Dits et écrits, volume III : 1976-1979, Paris, Gallimard, 1994, p. 29.

81 Foucault, "Il faut défendre la société », p. 154.
} 
qual se encontraria a filosofia política evocada no início quanto aos limites de uma reflexão sobre a política que suprimiria invariavelmente a alma discordante? É suficiente aqui simplesmente inverter a relação entre guerra e política e subordinar esta última à primeira? É que essa inversão da fórmula de Clausewitz não faz cair numa visão eminentemente belicosa da vida política em que a guerra traduziria uma hostilidade radical que, contrariamente a Schmitt, Foucault hesitaria em admitir ${ }^{82}$ ? Mais fundamentalmente, essa inversão não conduziu Foucualt a perder de vista tanto a especificidade da guerra como a da política? Pode-se, com efeito, reduzir a ação política a uma forma de guerra ${ }^{83}$ sem também arriscar, fazendo da guerra o "assunto permanente das relações sociais" e marcando "do sinal da guerra todo o corpo social ${ }^{84}$, de perder de vista a especificidade mesma do "político"85?

Essas interrogações são importantes e Foucault não nos oferece aparentemente alguma pista permitindo respondê-la. Mas, trata-se aqui dos limites de seu próprio pensamento que dos limites mesmo do pensamento político. Isso que suas interpretações negligenciam com efeito, é o que Foucault põe mais claramente em evidência em sua tentativa de refletir sobre uma inversão da relação entre guerra e política sem, portanto, querer sobre essa base desenvolver uma verdadeira teoria do poder, é que os conflitos e as disputas surgem da vida política e que se, ao contrário, eles estão vivos é porque eles são uma forma de antítese obrigatória que se deveria obrigatoriamente suprimir para se existir ${ }^{86}$. Assim, e num contexto largamente dominado

82 Michel Foucault : « L'œil du pouvoir [1977] », em Michel Foucault, Dits et écrits, p. 206. Hanssen (Critique of Violence, p. 157) coloca às luzes os termos desta tensão que atravessa o pensamento de Foucault.

83 Venturino, « À la politique comme à la guerre? », p. 151.

${ }^{84}$ Foucault, "Il faut défendre la société », p. 140.

85 Mark Neocleous : «Perpetual War, or "War and War Again". Schmitt, Foucault, Fascism », Philosophy \& Social Criticism, 22, 2, 1996, p. 47-66.

${ }_{86}$ Assim se explica o deslocamento teórico que, da problemática muito simplista da guerra, conduzirá rapidamente Foucault a privilegiar nos anos se186 - Universidade Católica de Pernambuco 
por uma opinião liberal fazendo da reconciliação e do consenso um verdadeiro standard moral em matéria de filosofia política, a questão tal como a põe Foucault consistiria em pensar a política sem constantemente procurar "evitar [...] as questões [...] sujeitas a controvérsias" ${ }^{87}$ que parecem constantemente fazer ecoar essas tentativas de reconciliação e sem eclodir sem cessar o consenso.

Evitar essas questões é fazer possível se representar filosoficamente uma ordem que se estimará potencialmente consensual, certamente, mais ao preço muito elevado de uma neutralização pelo próprio pensamento das relações de poder que o tem precisamente tornado necessário: relações de poder que, ressurgindo, acabam um dia ou outro por fragilizar a reconciliação. É essa aporia a qual é confrontada à filosofia política, a saber, a dizer a incapacidade de se representar filosoficamente o conflito e as disputas, dito de outro modo, neutralizando-o politicamente, que Foucault faz, por assim dizer, aparecer à luz do dia invertendo a relação entre guerra e política.

guintes a problemática mais complexa e mesmo mais rica da governamentalidade.

Consultar Michel Foucault : Sécurité, territoire, population. Cours au Collège de France. 1977- 1978, Paris, Hautes Études/Gallimard/Seuil, 2004; Michel Foucault, Naissance de la biopolitique, Cours au Collège de France. 1978-1979, Paris, Hautes études/Gallimard/Seuil, 2004

87 Segundo a fórmula de John Rawls : « La théorie de la justice comme équité: une théorie politique et non pas métaphysique [1985], traduit par Catherine Audard, dans John Rawls : Justice et démocratie, Paris, Seuil, 1993, p. 214. 